\title{
Performance Assessment of Shredded Polythene Fired Cement Clay Bricks for Sustainable Drive
}

\author{
Ojiako Marcel Oraegbune, Maxwell Solomon Soji* \\ Department of Building, Modibbo Adama University of Technology, Yola, Nigeria \\ Email address: \\ ssmaxwell0089@gmail.com (M. S. Soji), irokom0013june@gmail.com (O. M. Oraebuge) \\ ${ }^{*}$ Corresponding author
}

\section{To cite this article:}

Ojiako Marcel Oraegbune, Maxwell Solomon Soji. Performance Assessment of Shredded Polythene Fired Cement Clay Bricks for Sustainable Drive. International Journal of Science and Qualitative Analysis. Vol. 4, No. 2, 2018, pp. 38-41.

doi: $10.11648 /$ j.ijsqa.20180402.12

Received: December 22, 2017; Accepted: January 16, 2018; Published: February 26, 2018

\begin{abstract}
The need for maximum disposal of wastes and conservation of scarce resources or materials into useable building materials need to be underscored. Therefore, this study attempts to evaluate the use of polythene bag wastes in the building industry. The polythene bags waste (pure water sachets bags) were collected in dumping sites in Yola metropolis and were manually shredded to about $(5 \times 10) \mathrm{mm}$ sizes. Fired Cement clay (FCC) bricks incorporating the polythene waste were produced at a mix ratio of 1:8 and water/cement ratio of 0.5. Samples were tested for compressive strength at 7, 14, 21 and 28days hydration period while the water absorption and thermal conductivity test were evaluated at 28 days hydration period. Result of the compressive strength for the FCC Bricks at 28 days hydration period was between 0.00 and $2.33 \mathrm{~N} / \mathrm{mm}^{2}$, with $10 \%$ FCC having the highest compressive strength and least water absorption values of $2.01 \mathrm{~N} / \mathrm{mm}^{2}$ and $85 \mathrm{Kg} / \mathrm{mm}^{3}$ respectively. The compressive strength and thermal conductivity of all sampled FCC bricks decrease with increase percentage content of shredded polythene bags waste. The study found that thermal conductivity values of the FCC bricks was in the range of $1.48 \mathrm{w} / \mathrm{mk}$ and $1.8 \mathrm{w} / \mathrm{mk}$. The study therefore recommends $10 \% \mathrm{FCC}$ as suitable for use in areas where thermal transfer and rising dampness is of interest. Furthermore, the study concludes that reuse of the polythene bag wastes as building material or resources will help in reducing environmental hazards.
\end{abstract}

Keywords: Bricks, Compressive Strength, Environment Waste, Sustainable, Pollution

\section{Introduction}

The environmental impact arising from discarded polythene is evident in Nigeria with plastic bags waste littered everywhere especially the popular pure water bags [1]. [2] opined that, a substantial growth in the consumption of plastic is observed all over the world in recent years, which also increases the production of plastic-related waste. Polythene as a non-degradable material poses serious effects to the environment ranging from blockage of drainages to prevention of rain water percolation into the soil. Driven by these situations, researchers have intensified efforts to identify alternative ways to reuse polythene bags and its use in mortar and concrete proves to be one of the promising options. According to [2], polythene bags waste aggregates can be used successfully to replace conventional aggregates in mortar and concrete without any long term detrimental effects and with acceptable strength development properties. [1] Carried out a study on performance evaluation of shredded polythene concrete and recommended that shredded polythene can be suitably used as additive in concrete production for construction purposes, especially in areas where damp penetration under foundation is a challenge to completed buildings.

Plastics are subspecies of a class of materials known as polymers. They are composed of large molecules, formed by joining many, often thousands of smaller molecules (monomers) together [3]. Plastics are made from lowmolecular-weight monomer precursors, organic materials which are mostly derived from petroleum that are joined together by a process called polymerization. Plastics can be stiff and hard or flexible and soft. Because of their light weight, low cost, and desirable properties, their use has 
rapidly increased and they have replaced other materials such as metals and glass. They are used in millions of items which include cars, bullet-proof vests, toys, hospital equipment, and food containers [3]. Despite all its advantages, it is harmful as it plays a vital role in the occurrence of many public health problems [1]. A brick is a building material used to make walls, pavements and other elements in masonry construction. Traditionally, the term brick referred to a unit composed of clay, but it is now used to denote any rectangular units laid in mortar. A brick can compose of claybearing soil, sand, and lime, or concrete materials. Bricks are produced in numerous classes, types, materials, and sizes which vary with region and time period, and are produced in bulk quantities [4]. Two basic categories of bricks are fired and non-fired bricks (Bricks Industry Association). Fired bricks are one of the longest-lasting and strongest building materials, sometimes referred to as artificial stone, and have been used since circa 5000 BC. Air-dried bricks, also known as mud bricks, have a history older than fired bricks, and have an additional ingredient of a mechanical binder such as straw [5]. Fired bricks are burned in a kiln which makes them durable. Modern, fired, clay bricks are formed in one of three processes - soft mud, dry press, or extruded. Depending on the country, either the extruded or soft mud method is the most common, since they are the most economical [6]. According to [7], normally, bricks contain the following ingredients: Silica (sand) $-50 \%$ to $60 \%$ by weight, Alumina (clay) $-20 \%$ to $30 \%$ by weight, Lime -2 to $5 \%$ by weight, Iron oxide $-\leq 7 \%$ by weight, Magnesia - less than $1 \%$ by weight. Studies by [8] analyzed the engineering properties and cost of production of cement stabilized clay bricks and sandcrete blocks with a view to comparing the findings with cement stabilized clay bricks and hollow sandcrete blocks sold in Jimeta area of Yola, Adamawa State, Nigeria. And documented that averagely, liquid limit is 58.5, plastic limit is 35.69 and plasticity index is 22.82 for the clay soil which favorably compared with recommended classifications, locally and internationally. The results further indicate that the compressive strength of the clay bricks for different mix ratios range from $1.14 \mathrm{~N} / \mathrm{mm}^{2}-1.49 / \mathrm{mm}^{2}$ as curing age increases from 7 to 28 days, considering cement/clay mix ratio of $1: 12$. Cement/clay ratio of $1.5: 12$ gives a compressive strength of $1.2 \mathrm{~N} / \mathrm{mm}^{2}-1.47 \mathrm{~N} / \mathrm{mm}^{2}$ for the same 7 to 28 days. Results also indicate that the compressive strength of $225 \mathrm{~mm}$ and $150 \mathrm{~mm}$ sandcrete hollow blocks vary from $0.85 \mathrm{~N} / \mathrm{mm}^{2}$ to $1.33 \mathrm{~N} / \mathrm{mm}^{2}$ for cement $/$ sand mix ratio $1: 12$ and $0.92 \mathrm{~N} / \mathrm{mm}^{2}$ to $1.39 \mathrm{~N} / \mathrm{mm}^{2}$ for mix ratio $1.5: 12$ respectively; for curing period of 7 to 28 days. The study recommends a reduction in the cement/sand and cement/clay mix ratios employed for both sandcrete hollow blocks and cement stabilized clay bricks to ratio $1: 8$ or $1: 7$ to enable the blocks to achieve the recommended $2-2.5 \mathrm{~N} / \mathrm{mm}^{2}$ compressive strength for load bearing wall component in building. Similarly, [9] carried out a study on properties of fly ash bricks and reported that bricks produced were about $29 \%$ lighter than clay bricks. The compressive strength of bricks manufactured from fly ash possessed higher compressive strength of $20 \mathrm{MPa}$. This generally exceeds the best of load carrying clay bricks available by more than $25 \%$ and is several times better than acceptable commercially available common clay bricks. In general bricks are made by top fertile agricultural soil but by using fly ash, 28 percent of top fertile agricultural soil is saved. Use of fly ash in brick making also is beneficial in diverse ways. As compared to conventional clay bricks, fly ash bricks are stronger, more durable and yet more economical. Also, the process of fly ash brick manufacturing results in lesser pollution. A studies by $[10,11,12]$ on the possibility of using polythene fibres to increase the strength of sandcrete blocks without increasing the weight and cost of production with the addition of $0.25 \%$, $0.5 \%$ and $0.75 \%$ shredded polythene bags, revealed that the addition of polythene fibre to sandcrete blocks has very little effect on the compressive strength, although at $0.5 \%$ fibre content, the tensile strength increased. They study further reported that the compressive strength of the heated blocks is higher than the non -heated blocks. Finally, they reported that at an optimum fibre content of $0.5 \%$, fibres are good in reinforcing sandcrete blocks if heated. The research concludes that addition of polythene fibres to sandcrete blocks will increase the tensile strength of sandcrete blocks and can limit the propagation of cracks.

It is based on the aforementioned; that this study intends to determine an optimum quantity of shredded polythene waste that can be added to fired cement clay bricks without affecting the structural integrity of the fired clay bricks, with the aim of creating friendly environment through the reuse of polythene bags waste.

\section{Methodology}

The tests were carried out in the department of Civil Engineering, Adamawa State Polytechnic. The pure water waste bags used was sourced from dump sites of within the Yola metropolis, Adamawa State and subjected to treatment by washing with clean water in order to get rid of dirt and other stains before manually shredding them to an average size of $5 \times 10 \mathrm{~mm}$ using scissors. Mix ratio 1:8 was adopted in this research. Constant water/cement ratio of 0.5 was used. Four mixes were produced with each having a different percentage of the polythene. The bricks were coded as $0 \%$ FCC, $10 \%$ FCC, 20\% FCC and 30\% FCC. These proportions were just chosen and not informed by any previous research. 12 (Twelve) 6 inches cement clay bricks were produced, mixing was done manually and the block moulding machine was used to produce the cement clay bricks. The bricks were then fired to a temperature $100^{\circ} \mathrm{C}$ and the samples were cured by spraying water three times daily for 28days. The compressive strength test was measured at 7, 14, 21 and 28days hydration period while the water absorption and thermal conductivity test were determined at 28 days curing period. All tests were carried out on three bricks sample of each percentage addition and the average results of the test were used in this work. The K- value, (Thermal conductivity) was determined using the formulae in Equation 1 


$$
K=\frac{Q X}{A \Delta T}
$$

Where $\mathrm{Q}=$ Quantity of Heat Used, $\mathrm{X}=$ Thickness of Sample, $\mathrm{A}=$ Area of Sample,

$\Delta \mathrm{T}=$ Change in temperature

\section{Results and Discussion}

\subsection{Compressive Strength}

Results of average compressive strength development with curing period of 7, 14, 21 and 28days are presented in Table 1. The average compressive strength of fired cement clay bricks at 28 days hydration period indicate $2.13 \mathrm{~N} / \mathrm{mm}^{2}$ for the control mix $\left(0 \%\right.$ FCC) while $2.01 \mathrm{~N} / \mathrm{mm}^{2}$ and $1.15 \mathrm{~N} / \mathrm{mm}^{2}$ was obtained for $10 \%$ FCC and $20 \%$ FCC respectively which is below the range of 2.5 to $3.45 \mathrm{~N} / \mathrm{mm}^{2}$ specified by Nigerian Industrial Standard NIS [13]. At 7days hydration period, 10\% FCCdeveloped about $80 \%$ of it 28 days hydration period strength also the sample with $20 \%$ FCC developed about $70 \%$ of it 28days hydration period strength. This suggests that a substantial amount of strength is developed within the first 7days of hydration. The low compressive strength is likely due to the poor bonding between the clay and the shredded polythene bags waste, which is as a result of the smooth surface of the shreds as reported by [1].

Table 1. Compressive Strength of the Fired Cement Clay Bricks with curing days $\left(\mathrm{N} / \mathrm{mm}^{2}\right)$.

\begin{tabular}{lllll}
\hline SAMPLE & & & \\
\hline & 7days & 14days & 21days & 28days \\
\hline $0 \%$ FCC & 2.05 & 2.07 & 2.11 & 2.13 \\
$10 \%$ FCC & 1.54 & 1.65 & 1.92 & 2.01 \\
$20 \%$ FCC & 0.71 & 1.05 & 1.09 & 1.15 \\
$30 \%$ FCC & 0.00 & 0.00 & 0.00 & 0.00 \\
\hline
\end{tabular}

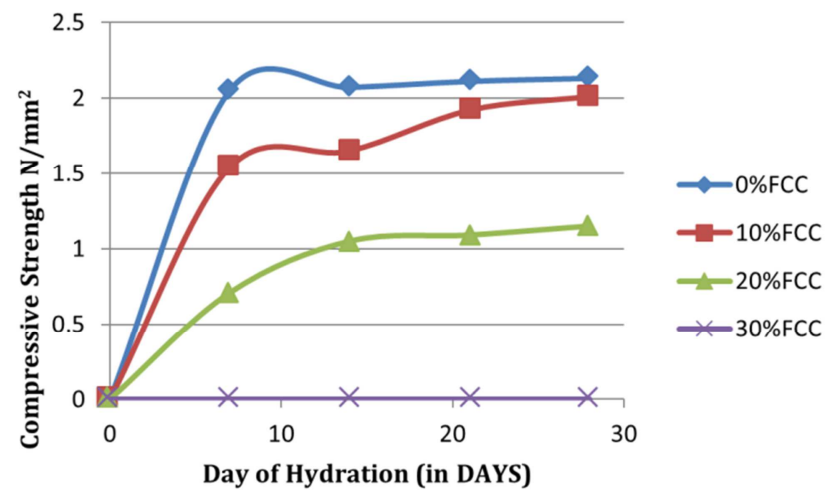

Figure 1. Variation of Compressive strength $\left(\mathrm{N} / \mathrm{mm}^{2}\right)$ with hydration days.

Table 2. Water absorption rate of the Fired Cement Clay bricks at 28 days hydration.

\begin{tabular}{lllll}
\hline SAMPLE & & & & \\
\hline & Wet weight $\left(\mathbf{K g} / \mathbf{m m}^{\mathbf{3}}\right)$ & Dry weight $\mathbf{( K g / \mathbf { m m } ^ { \mathbf { 3 } } )}$ & Change in weight $\mathbf{( K g / \mathbf { m m } ^ { \mathbf { 3 } } )}$ & Water Absorption $\left.(\mathbf{K g} / \mathbf{m m})^{\mathbf{3}}\right)$ \\
\hline $0 \%$ FCC & 1.98 & 1.89 & 0.09 & 90 \\
$10 \%$ FCC & 1.73 & 1.65 & 0.08 & 85 \\
$20 \%$ FCC & 1.56 & 1.35 & 0.21 & 120 \\
$30 \%$ FCC & 1.30 & 1.21 & 0.09 & 90 \\
\hline
\end{tabular}

\subsection{Water Absorption}

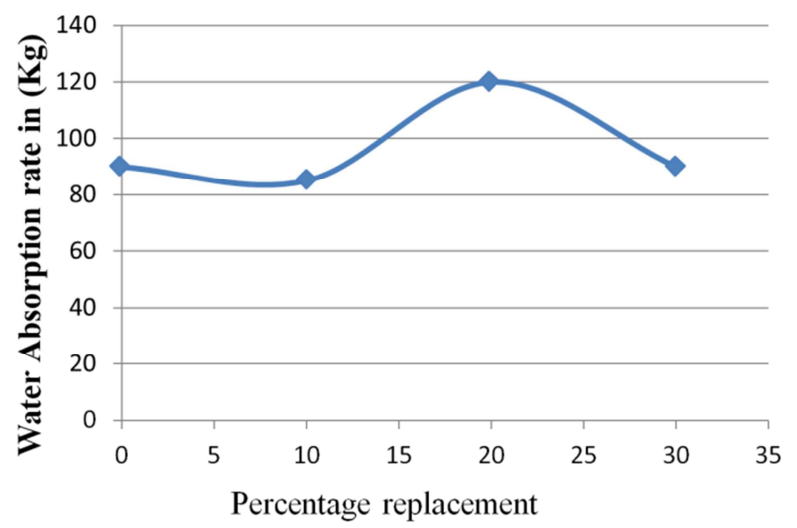

Figure 2. Water absorption rate $\left(\mathrm{Kg} / \mathrm{mm}^{3}\right)$ of the FCC Bricks at 28days hydration.

Results of water absorption capacities of the fired cement clay bricks are presented in Table 2 and Figure 2. Fired cement clay bricks of $100 \times 100 \times 100 \mathrm{~mm}$ were used for the water absorption test in for ease of handling. The water absorption capacities for all the fired cement clay bricks reveals that almost all the fired cement clay bricks have lower water absorption capacities than the maximum limit recommended in ASTM C - 140 of $240 \mathrm{~kg} / \mathrm{m}^{3}$. However the control sample $0 \%$ FCC and the $10 \%$ FCC have a better water absorption property of $85 \mathrm{~kg} / \mathrm{m}^{3}$ while the water absorption rate for the $20 \%$ FCC and $30 \%$ FCC were $120 \mathrm{~kg} / \mathrm{m}^{3}$ and $90 \mathrm{~kg} / \mathrm{m}^{3}$ respectively. This means that $10 \%$ FCC can be use in water logged areas and get same result as when using the normal sandcrete blocks without any addition of shredded polythene bags waste as reported by $[10,12]$

\subsection{Thermal Conductivity}

The result of the thermal conductivity test carried out on the shredded polythene waste Fired Cement clay bricks samples are shown in Table 3. The thermal conductivity result showed that, the thermal conductivity value decreases from $1.8,1.48,1.31$ and $1.27 \mathrm{~W} / \mathrm{mk}$ for $0 \% \mathrm{FCC}, 10 \% \mathrm{FCC}$, $20 \%$ FCC and $30 \%$ FCC respectively with increase in the percentage of shredded polythene bags waste, which can be attributed largely due to polythene being a poor conductor of heat [1]. However, the thermal conductivity of normal concrete is within the range of $1.5-3.5 \mathrm{~W} / \mathrm{mk}$ as stipulated by [1]. The results obtained found that for $10 \%$ FCC and $20 \%$ FCC there was a reduction in thermal conductivity but within the range of $7-16 \%$ of the Control, $0 \%$ FCC. This indicates 
that the addition of shredded polythene bags waste can improve the thermal conductivity of Fired Cement Clay Bricks, which would in turn result in reduction in the rate of heat transfer from the environment into the building and vice versa $[1,11]$.

Table 3. Thermal Conductivity (K-value) of the fired cement clay bricks at 28 days hydration.

\begin{tabular}{lllll}
\hline Sample & $\mathbf{0 \%}$ FCC & $\mathbf{1 0 \%}$ FCC & $\mathbf{2 0 \%}$ FCC & $\mathbf{3 0 \%}$ FCC \\
\hline K-value W/ Mk & 1.8 & 1.68 & 1.52 & 1.48 \\
\hline
\end{tabular}

\section{Conclusion}

This study with the aim of assessing the performance of Fired polythene bags bricks conclude that:

The FCC bricks all have lesser compressive strength compare with the control bricks the at all hydration period. The compressive strength of the FCC bricks decreases with increase in the volume of the shredded polythene bags waste added, which can largely be attributed to poor bonding of the polythene bag waste and other materials.

2. The thermal conductivity of the FCC bricks was found to be good compared to the samples without the polythene waste, making it suitable for use as walling material in areas where thermal transmission is of interest.

3. The study found that the water absorption rate of $0 \%$ FCC and 30\% FCC were the same. However, 10\% FCC has the least value of $85 \mathrm{Kg}$. Although all the FCC bricks falls below the maximum water absorption rate limit specified in ASTM (140), making the bricks suitable for use in damp areas.

\section{References}

[1] Anum I. (2012), Performance Evaluation of Shredded Polythene Concrete. M. Sc. Construction Technology Thesis in the Department of Building. University of Jos.
[2] Saikia, N. \& Jorge, L. (2012). Use of plastic waste as Aggregate in cement mortar and Concrete preparation. Construction and Building material.

[3] Stein, S \& Richard S. (2004) "Plastic." Pollution A to Z 2004. Retrieved on 21 Apr. 2015 http://www.encyclopedia.com.

[4] Muttapilly M. J. et al. (2007), Disposal of Plastic Waste in the Domestic Environment. A case study from India. Epidemiology. vol 18.

[5] Campbell, J. W \& Pryce, W (2003). Brick: a world history. London and New York. Thomas and Hudson.

[6] Punmia, B. C \& Jain, A. K (2003). Basic Civil Engineering 33: 66-78.

[7] Kenoyer, Jonathan Mark (2005). Uncovering the keys to the lost industries. American Scientific Journal 15: 24 -33.

[8] Isa, F. N (2009). Assessment of engineering properties and cost of production of cement stabilized clay bricks and sandcrete blocks. An undergraduate project FUT, Yola.

[9] Tok, P. (2015). A Study on Properties of Fly Ash Bricks. An undergraduate project Unijos.

[10] Ijalana, F. B, Afolayan, J. O and Adeleke (2016). Effects of Polythene Fibres on Selected Properties of Sandcrete Blocks. Nigerian Journal of Technology (NIJOTECH) 35 (1): 37-42.

[11] Ogi, K., Shinodab, T \& Mizuic, M. (2005). Strength in concrete reinforced with recycled CFRP pieces. Composites Part A: Applied Science and Manufacturing, (36): 893-902.

[12] Omoregie, A. (2013), Optimum Compressive Strength of Hardened Sandcrete Building Blocks with Steel Chips. Academic Journals Available online http:/www.academicjournals.org/JETR. (3): 209-215.

[13] NIS 2000. NIS 87: (2004). Nigerian Industrial Standard: Standard for Sandcrete Blocks. Standards organization of Nigeria. 